\title{
Digital archiving the space and memory of Kyoto across space and time using GIS
}

\author{
Naomi KAWASUMI ${ }^{\text {a, }}$, Hirotaka SATO ${ }^{\text {a }}$, Shunpei YAMAMOTO ${ }^{\text {a }}$ and Keiji YANO ${ }^{\text {a }}$ \\ ${ }^{a}$ Ritsumeikan University,Japan; n-kawa@fc.ritsumei.ac.jp,lt0114rr@gmail.com,lt0465xr@ed.ritsumei.ac.jp, \\ yano@lt.ritsumei.ac.jp
}

Keywords: Digital Humanities, GIS database, Open data, Large-scale Maps of Kyoto City, Modern Kyoto

\begin{abstract}
:
Digital Humanities (DH) is expected to generate new knowledge within traditional Humanities including history, literature, and the arts. DH utilizes computational media to conduct research on concepts such as consciousness and awareness, then analyzes, integrates and presents the outcomes. GIS has become widespread within DH research (Yano et al. 2011). This study aims to consider the archiving of various information concepting Kyoto using GIS. It also aims to understand landscape value in Kyoto.
\end{abstract}

Since Heian-Kyo, Kyoto has existed for over 1,200 years of history. So, it is necessary to collect various information about Kyoto such as literature, art, maps, and photographs for research on the urban history of Kyoto. The digitalization and construction of a GIS database are useful to preserve and release information about Kyoto.

The Digital Archive of the Historical City of Kyoto that we are aiming to produce includes content such as literary works, paintings, photographs, and intangible cultural assets like festivals including the Gion Festival, traditional arts, and memories. Them did not simply listed in a database but had released with geospatial information, such as maps, as a platform linked to place.

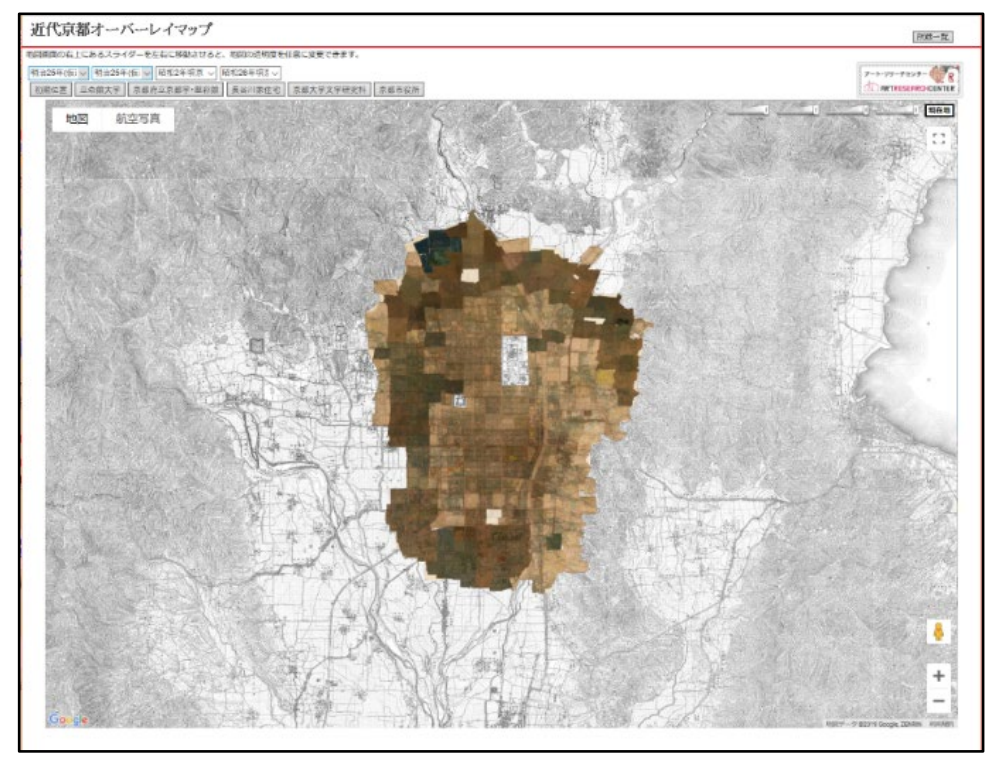

Figure 1. "Overlaying maps of modern Kyoto". (https://www.arc.ritsumei.ac.jp/archive01/theater/html/ModernKyoto/)

In 2016, we published the overlaying maps of modern Kyoto, which focus on between the Meiji Period and immediately after the Second World War (Figure 1). It uses archives such as a "tentative topographic map" from the middle of the Meiji Period, "City Planning Basic Maps" from the Taisho to early Showa periods, and an "official topographic map" published in 1912 (Taisho 1). The strong point of this web-based map system is that one can display several maps as overlays over Google Maps.

Additionally, roughly 2,000 photographs of the Kyoto City Tram system from around the 1960s were archived. The research group identified places reflected in the photographs with the collaboration of experts and released those photographs and data with location information. There were some pictures whose location could not be identified. 
We also added a system that allows people from the outside to enter information into the published database. Furthermore, the Kyoto Memory Map Project was launched, and memories of places and periods reflected in old photographs and maps are also being collected and released.

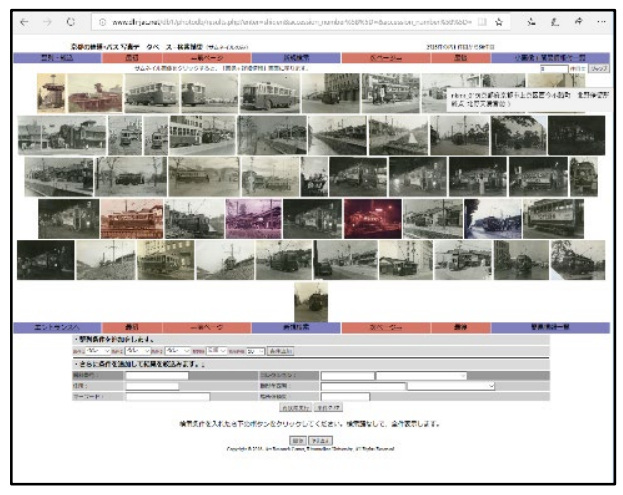

1) List of photographs

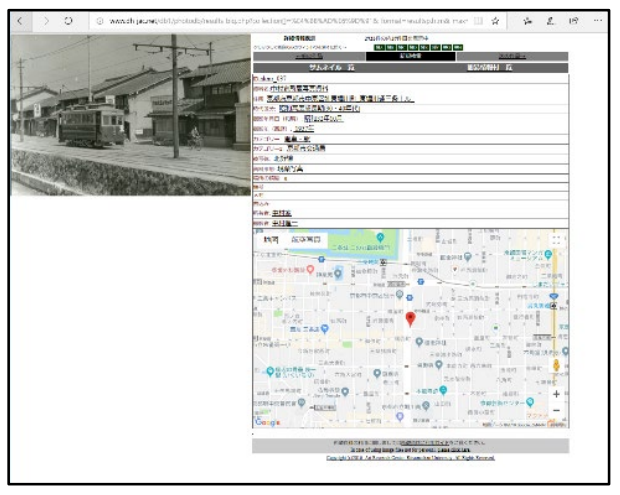

2) Metadata of photograph

Figure 2. "Kyoto City Tram and Bus Photograph Database". (http://www.dh-jac.net/db1/photodb/search_shiden.php)

The digital achieving and release of information are valuable for urban history research about Kyoto. It is a treasure trove of historical and geographical documents that are useful for researchers. Recently, a discussion on the occupation of Kyoto after the Second World War was published using maps accumulated in this way. In this case, the GIS database of "Large-Scale Maps of Kyoto City" (Kyoto-shi meisai-zu) owned by the Kyoto Institute, Library and Archives was used. Some administrative documents concerning occupied Kyoto owned by the Kyoto Institute, Library and Archives were shown in spring 2010. One is a document about the car accidents that the Occupation Army caused in Kyoto during the Occupation period. Another is a document concerning the buildings confiscated by the Occupation Army. These documents have positional information, so that previous research mapping these data by hand becomes important in understanding occupied Kyoto (Nishikawa, 2017). Below, we examine the contents of the maps based on the results of the study of occupied Kyoto.

In the Kyoto Institute, Library and Archives, some administrative documents on occupied Kyoto are stored. They include documents about car accidents and confiscated buildings. Some buildings were confiscated for use by the Occupation army. In this paper, we call buildings used for businesslike operation by the Occupation Army "confiscated establishments" and buildings used for dwellings by the Occupation Army "confiscated houses." We constructed vector data for each confiscated building based on the positional information to improve the precision of previous research and facilitate the comparison of maps. Additionally, memories of this period were collected and constructed GIS database, so administrative documents and memories were linked with the maps (Figure 3). The current condition of occupying Kyoto and the living conditions of local residents in this period then became clear (Nishikawa, 2017).

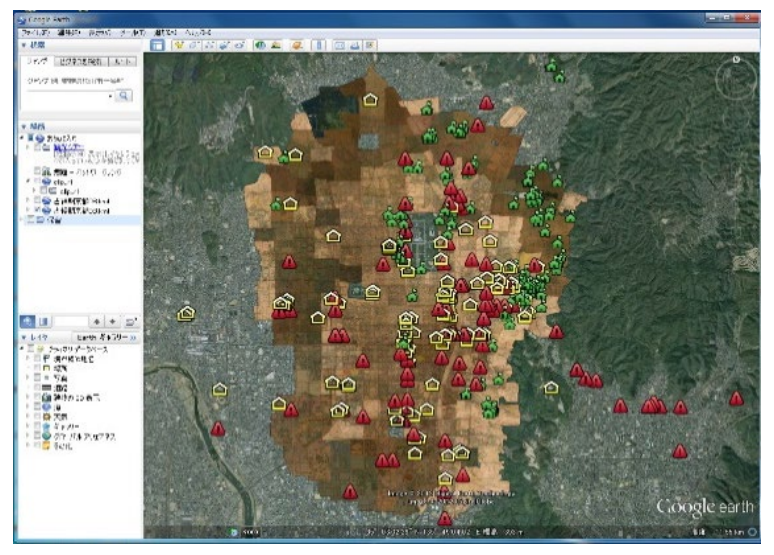

Figure 3. Map of Occupied Kyoto City.

Interdisciplinary research is progressing using archived information. Also, the archives are widely used as sightseeing and learning tools for the general public. It is also meaningful as a material to understand the past, including in the field of community development by residents, which has flourished in the recent years. The archive is treasure trove of historical and geographical information that is useful for Digital Humanities research. 